\title{
Khu hệ động vật không xương sống cỡ lớn ven bờ ở hồ Đankia, tỉnh Lâm Đồng
}

\section{Littoral macroinvertebrates in Dankia lake in Lam Dong province}

\author{
Lê Văn Thọ ${ }^{*}$, Đặng Văn Sơn ${ }^{1}$, Trần Ngọc Diễm $\mathrm{My}^{2}$, \\ Phan Doãn Đăng ${ }^{1}$, Nguyễn Thị Mai Hương ${ }^{1}$ \\ ${ }^{1}$ Viện Sinh học Nhiệt đới, VAST, Việt Nam \\ ${ }^{2}$ Trường Đại học Khoa học Tự nhiên, VNU-HCM, Việt Nam \\ "Tác giả liên hệ, Email: tho1010@ gmail.com
}

\section{THÔNG TIN}

DOI: $10.46223 / \mathrm{HCMCOUJS}$.

tech.vi.15.1.1023.2020

Ngày nhận: 19/11/2019

Ngày nhận lại: 11/09/2020

Duyệt đăng: 25/10/2020

\section{Tù khóa:}

chỉ số đa dạng, động vật không xương sống cỡ lớn ven bờ, hồ Đankia, phân bố, thành phần loài

Keywords:

diversity indices, littoral

macroinvertebrates, Dankia lake, species composition

\section{TÓM TẮT}

Các loài động vật không xương sống cỡ lớn sống ở khu vực ven bờ được khảo sát trong hai mùa (mùa mưa và mùa khô) trong 5 năm từ 2013 đến 2017 tại 5 điểm thu mẫu ở hồ Đankia, tỉnh Lâm Đồng. Kết quả đã xác định được 23 loài thuộc 15 họ, 9 bộ, 4 lớp, 3 ngành gồm: ngành chân khớp có số loài cao nhất (18 loài), tiếp theo là ngành thân mềm (4 loài) và thấp nhất là ngành giun đốt (1 loài). Tại các điểm thu mẫu, lớp côn trùng ghi nhận số loài (14 loài) cao nhất. Ngược lại, lớp giun ít tơ có số loài (1 loài) thấp nhất. Qua nghiên cứu cho thấy, số loài, mật độ cá thể và chỉ số đa dạng của động vật không xương sống cỡ lớn ven bờ ít có sự biến động giữa các điểm thu mẫu, nhưng có nhiều khác biệt theo mùa khảo sát. Trong đó, số loài và chỉ số đa dạng ghi nhận vào mùa mưa cao hơn mùa khô.

\begin{abstract}
The littoral macroinvertebrates communities in Dankia lake in Lam Dong Province were surveyed at five sampling sites in five years from 2013 to 2017. A total of 23 taxa belonging to 15 familes, nine orders, three phyla were identified. The arthropoda phylum had the highest diversity (18 species) followed by mollusca phylum (4 species) and the lowest diversity in the annelida phylum (1 species). Number of species of class insecta were the highest (14 species). Meanwhile class oligochaeta were the lowest (1 species). The number of species, density and Shannon diversity indices value of littoral macroinvertebrates were not variable through sampling sites, but they were seasonal changes. The number of species and Shannon diversity indices value in rainy season were higher than the dry season.
\end{abstract}

\section{Mở đầu}

Động vật không xương sống cỡ lớn ven bờ (Littoral Macroinvertebrates) là những loài động vật không có xương sống. Chúng sống ở trên hoặc gần đường bờ của các thuỷ vực như sông, 
suối, ao, hồ. Chúng là nhóm loài phong phú, đa dạng, phân bố rộng và đóng vai trò quan trọng trong hệ sinh thái thuỷ vực (MRC, 2010). Hiện nay, các loài này được sử dụng phổ biến để quan trắc, đánh giá và giám sát chất lượng nước cũng như sức khoẻ hệ sinh thái ở các thuỷ vực (MRC, 2010). Các nghiên cứu về khu hệ động vật không xương sống cỡ lớn ven bờ đã được thực hiện phổ biến ở khu vực sông Mê Kông (MRC, 2010; Ngo, Nguyen, Nguyen, Pham, \& Ngo, 2013), sông Sài Gòn (T. V. Le \& Do, 2015), các khu vực đất ngập nước như Láng Sen (T. V. Le et al., 2018), Trà Sư (Phan et al., 2011), hay khu vực hồ xử lý nước thải (T. V. Le, Phan, Tran, \& Huynh, 2015). Tuy nhiên, chưa có nghiên cứu nào được công bố về khu hệ động vật không xương sống cỡ lớn ven bờ ở khu vực hồ chứa, hồ cấp nước, trong đó có hồ Đankia ở tỉnh Lâm Đồng.

Hồ Đankia ở thuộc huyện Lạc Dương, tỉnh Lâm Đồng. Hồ được xây dựng năm 1942 để làm thuỷ điện. Đến năm 1984 hồ được sử dụng làm hồ cung cấp nước cho thành phố Đà Lạt. Hồ có diện tích lưu vực khoảng $123 \mathrm{~km}^{2}$ và diện tích mặt hồ khoảng 245 ha. Hiện nay diện tích mặt hồ Đankia giảm mạnh do hoạt động nông nghiệp của người dân và quá trình bồi lắng tự nhiên. Bên cạnh đó, các nguồn rác thải từ sinh hoạt, nông nghiệp và hoạt động du lịch tự phát hai bên bờ hồ đang gây ảnh hưởng nghiêm trọng đến chất lượng nước cũng như khu hệ sinh vật trong nước (N. T. N. Le \& Phan, 2015; Tran, Doan, Bui, \& Nguyen, 2015), đặc biệt nhóm các loài thuỷ sinh vật như: động vật, thực vật phù du và động vật không xương sống cỡ lớn chịu ảnh hưởng nhiều nhất. Trong đó, khu hệ thực vật và động vật phù du đã được N. T. N. Le và Phan (2015), Tran và cộng sự (2015) nghiên cứu và công bố, riêng khu hệ động vật không xương sống cỡ lớn ven bờ ở khu vực hồ chưa có công trình nghiên cứu nào. Bài báo này là kết quả nghiên cứu về khu hệ động vật không xương sống cỡ lớn ven bờ ở khu vực hồ Dankia trong 5 năm từ 2013 đến 2017.

\section{Vật liệu và phương pháp nghiên cứu}

\subsection{Thò̀i gian và địa điểm}

Các mẫu động vật không xương sống cỡ lớn ven bờ được thu tại 05 điểm ở khu vực hồ Đankia, tỉnh Lâm Đồng. Các mẫu được thu 2 đợt/năm từ năm 2013 đến năm 2017. Hàng năm, mẫu được thu 1 đợt vào mùa khô (tháng 5 ) và 1 đợt vào mùa mưa (tháng 10 ). Vị trí các điểm thu mẫu được ký hiệu từ DK1 đến DK5. Vị trí các điểm thu mẫu như Hình 1.

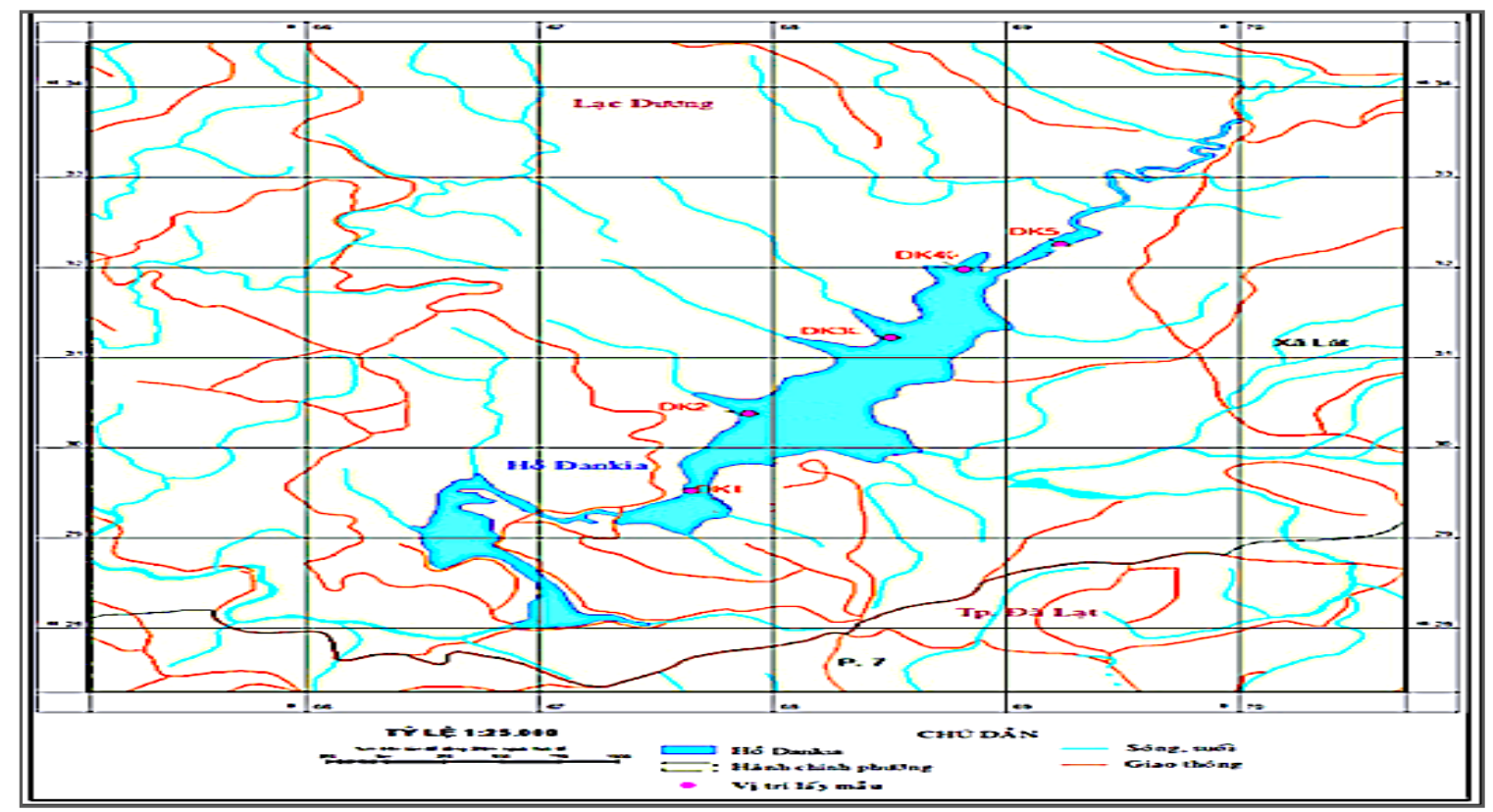

Hình 1. Bản đồ vị trí các điểm thu mẫu ở hồ Đan Kia

Ghi chú: DK1: Khu vực đập Đankia; DK2: Khu vực nhà máy nước hồ Đankia; DK3: Khu vực giữa hồ Đankia; DK4: Khu vực gần cuối hồ; DK5: khu vực cuối hồ 


\subsection{Phưong pháp thu mẫu}

Phương pháp thu mẫu động vật không xương sống cỡ lớn ven bờ được thực hiện dựa theo hướng dẫn của Uỷ hội sông Mê Kông năm 2010 (MRC, 2010). Tại các điểm thu mẫu, các mẫu được thu bằng vợt hình chữ $\mathrm{D}$ ở bờ bên phải của hồ. Tại mỗi điểm thu mẫu tiến hành lấy 4 mẫu. Mồi mẫu tiến hành 5 lần quét dọc bờ hồ khoảng $10 \mathrm{~m}$. Mẫu sau khi thu được cho vào khay nhựa màu trắng, sau đó cho vào lọ nhựa thể tích $500 \mathrm{ml}$ chứa Formalime $10 \%$. Các lọ mẫu được ghi nhãn vị trí lấy mẫu, ký hiệu mẫu, ngày thu mẫu. Mẫu sau đó được đưa về phòng thí nghiệm của Viện Sinh học nhiệt đới để nhặt mẫu và định danh.

\subsection{Phương pháp phân tích mẫu}

Trong phòng thí nghiệm, các mẫu sau khi thu về được nhặt và phân tích dưới kính lúp Olympus SZ-ST (Olympus, Tokyo, Nhật Bản). Các mẫu được phân loại, định danh tới giống hoặc loài. Mẫu được định danh bằng phương pháp hình thái dựa trên các khóa phân loại, các đặc điểm mô tả hình thái, môi trường sống, khu vực phân bố theo các tài liệu trong nước và nước ngoài của Dang, Thai, và Pham (1980), Nguyen, Pinder, và Tilling (2001), McCafferty (1983), Morse, Yang, và Tian (1994), Narumon và Boonsatien (2006), Rolf và Brandt (1974).

\subsection{Phưong pháp xử lý số liệu}

Các kết quả phân tích mẫu động vật không xương sống cỡ lớn ven bờ được xử lý thống kê. So sánh sự khác biệt theo không gian khảo sát (theo điểm thu mẫu) và theo thời gian khảo sát (theo mùa) bằng phân tích Two-way ANOVA và phân tích hậu kiểm theo phương pháp Tukey’s HSD test bằng phần mềm SPSS v.20 (IBM Corp., Armonk, New York, Mỹ). Tính chỉ số đa dạng Shannon-Weiner ( $\left.\mathrm{H}^{\prime}\right)$ bằng phần mềm Primer v6 (PRIMER-E Ltd, Plymouth, Anh).

\section{Kết quả nghiên cứu}

\subsection{Thành phần loài}

Kết quả khảo sát và phân tích khu hệ động vật không xương sống cỡ lớn ven bờ tại 5 điểm ở khu vực hồ Đankia vào tháng 5 và tháng 10 từ năm 2013 đến năm 2017 đã xác định được 23 loài thuộc 15 họ, 9 bộ, 4 lớp, 3 ngành, bao gồm: ngành chân khớp (Arthropoda) có thành phần loài đa dạng nhất với 18 loài thuộc 2 lớp, 7 bộ, tiếp theo là ngành thân mềm (Mollusca) ghi nhận được 4 loài thuộc 1 lớp, 1 bộ và thấp nhất là ngành giun đốt (Annelida) ghi nhận được 1 loài thuộc 1 lớp, 1 bộ (Bảng 1).

\section{Bảng 1}

Danh sách các loài động vật không xương sống cỡ lớn ven bờ ở hồ Đankia

\begin{tabular}{|c|l|c|l|}
\hline STT & \multicolumn{1}{|c|}{ Nhóm loài } & STT & \multicolumn{1}{|c|}{ Nhóm loài } \\
\hline & \multicolumn{1}{|c|}{ NGÀNH MOLLUSCA } & $\mathbf{1 1}$ & Chironomus sp. \\
\hline & \multicolumn{1}{|c|}{ Ló́p Gậ Mesogastropoda } & $\mathbf{1 2}$ & Kiefferulus sp. \\
\hline & \multicolumn{1}{|c|}{ Họ Lymnaeidae } & $\mathbf{1 3}$ & Thienemannimyia sp. \\
\hline $\mathbf{1}$ & Radix viridis (Quoy \& Gaimard, 1833) & $\mathbf{1 4}$ & Dicranota sp. \\
\hline & Họ Pilidae & & \multicolumn{1}{c|}{ Bộ Coleoptera } \\
\hline $\mathbf{2}$ & Pila polita Deshayes (1830) & & Họ Dryopidae \\
\hline $\mathbf{3}$ & Pomacea sp. & $\mathbf{1 5}$ & Dryops sp. \\
\hline
\end{tabular}




\begin{tabular}{|c|c|c|c|}
\hline STT & Nhóm loài & STT & Nhóm loài \\
\hline & Họ Viviparidae & & Bộ Ephemeroptera \\
\hline \multirow[t]{5}{*}{4} & Filopaulina sumatrensis polygramma (Martens, 1860) & & Họ Baetidae \\
\hline & NGÀNH ANNELIDA & 16 & Centroptilum sp. \\
\hline & Lớp Oligochaeta & & Bộ Hemiptera \\
\hline & Bộ Haplotaxida & & Họ Notonectidae \\
\hline & Họ Tubificidae & 17 & Nychia sp. \\
\hline \multirow[t]{5}{*}{5} & Limnodrilus hoffmeisteri Claparede (1862) & 18 & Notonecta sp. \\
\hline & NGÀNH ARTHROPODA & & Họ Naucoridae \\
\hline & Lớp Malacostraca & 19 & Naucoris sp. \\
\hline & Bộ Decapoda & & Bộ Odonata \\
\hline & Họ Palaemonidae & & Họ Calopterygidae \\
\hline 6 & Macrobrachium sintangense (De Man, 1898) & 20 & Calopteryx sp. \\
\hline 7 & Macrobrachium nipponese (De Haan, 1849) & & Họ Gomphidae \\
\hline 8 & Macrobrachium lanchesteri (De Man, 1911) & 21 & Gomphus sp. \\
\hline \multirow[t]{4}{*}{9} & Macrobrachium pilimanus (De Haan, 1879) & & Họ Libellulidae \\
\hline & Lớp Insecta & 22 & Celithemis sp. \\
\hline & Bộ Diptera & & Bộ Trichoptera \\
\hline & Họ Chironomidae & & Họ Dipseudopsidae \\
\hline 10 & Ablabesmyia sp. & 23 & Pseudoneureclipsis sp. \\
\hline 11 & Chironomus sp. & & \\
\hline
\end{tabular}

Nguồn: Kết quả phân tích dữ liệu của nhóm nghiên cứu

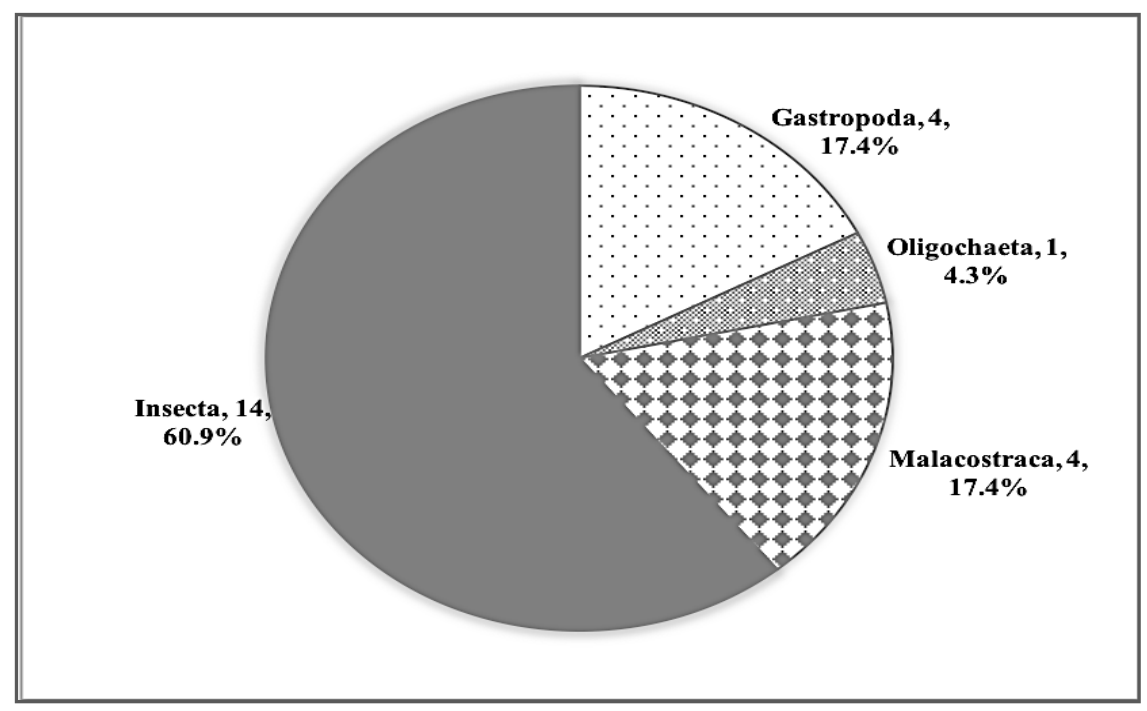

Hình 2. Số lượng các nhóm loài động vật không xương sống cỡ lớn ven bờ 
Trong số các lớp, lớp côn trùng (Insecta) có số loài cao nhất với 14 loài, chiếm tỷ lệ 60,9\%, tiếp theo là lớp giáp xác lớn (Malacostraca) và lớp thân mềm chân bụng (Gastropoda) cùng ghi nhận được 4 loài, cùng chiếm tỷ lệ $17,4 \%$. Lớp giun ít tơ (Oligochaeta) có số loài thấp nhất với 1 loài, chiếm tỷ lệ 4,3\% (Hình 2).

Số loài động vật không xương sống cỡ lớn ven bờ phân bố tại mỗi điểm thu mẫu trung bình dao động từ $1,5 \pm 0,2$ đến $2,5 \pm 0,4$ loài/điểm. Trong đó, số loài cao nhất tại điểm DK1 ở khu vực gần đập Đankia và thấp nhất tại điểm DK3 ở khu vực giữa hồ (Hình $3 \mathrm{a}$ ).

Phân tích sự khác biệt về số loài theo thời gian khảo sát và theo điểm thu mẫu bằng phân tích Two-way ANOVA cho thấy, số loài không có sự khác biệt giữa các điểm thu mẫu $(\mathrm{p}=0,056>0,05)$, nhưng có sự khác biệt giữa hai đợt khảo sát $(\mathrm{p}=0,002<0,05)$. Trong đó, trung bình số loài trong đợt khảo sát vào mùa mưa dao động từ $1,8 \pm 0,1$ đến $3,0 \pm 0,3$ cao hơn so với mùa khô với trung bình số loài dao động từ $1,3 \pm 0,1$ đến $2,1 \pm 0,2$ (Hình $3 b$ ).
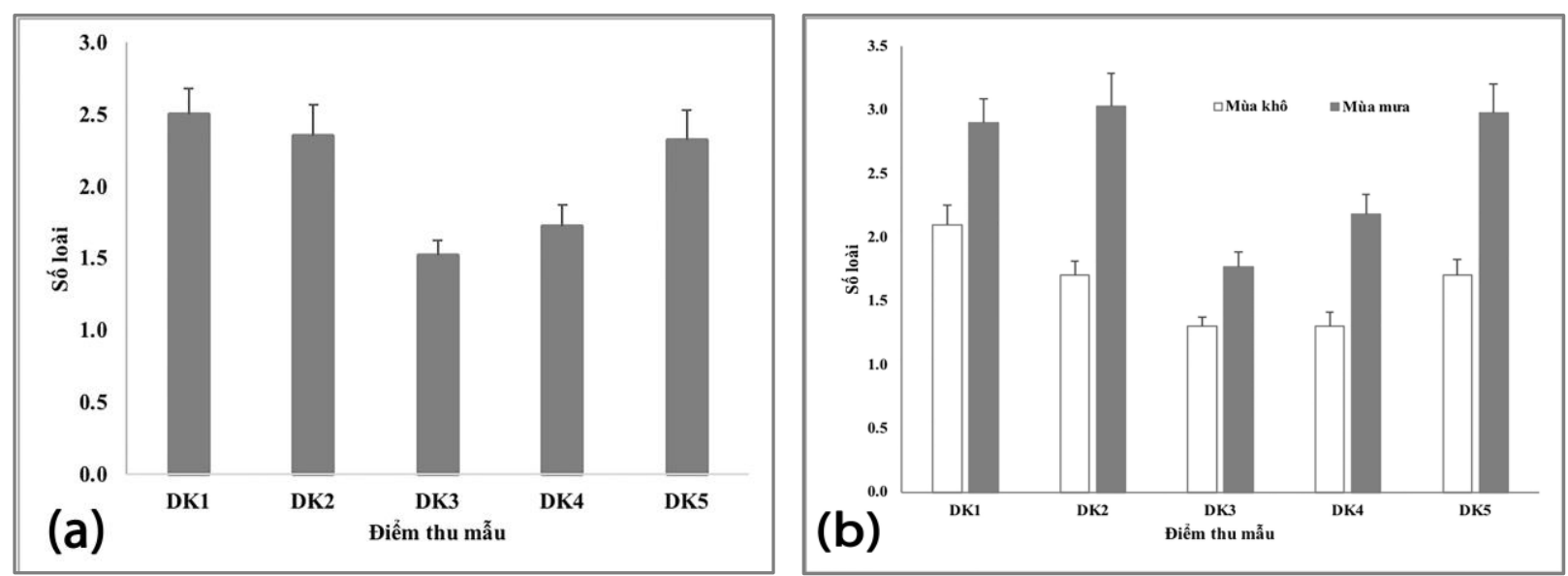

Hình 3. Số loài động vật không xương sống cỡ lớn ven bờ tại các điểm thu mẫu

\subsection{Mật độ cá thể và loài uu thế}

Mật độ cá thể của động vật không xương sống cỡ lớn ven bờ tại các điểm thu mẫu trung bình dao động từ $38,2 \pm 8,9$ đến $61,0 \pm 16,3$ cá thể/ $\mathrm{m}^{2}$. Trong đó, mật độ cá thể cao nhất tại điểm DK2 và thấp nhất tại điểm DK1 (Hình $4 \mathrm{a})$.

Phân tích sự khác biệt về mật độ cá thể của động vật không xương sống cỡ lớn ven bờ theo thời gian khảo sát và theo điểm thu mẫu bằng Two-way ANOVA cho thấy, mật độ cá thể không có sự khác biệt giữa hai mùa khảo sát $(\mathrm{p}=0,741>0,05)$ và giữa các điểm thu mẫu $(\mathrm{p}=0,157>0,05)$. Trong đó, trung bình mật độ cá thể trong đợt khảo sát mùa khô dao động từ $37,4 \pm 3,3$ đến $66,7 \pm 10,5$ cá thể/ $/ \mathrm{m}^{2}$ và trong đợt khảo sát mùa mưa dao động từ $29,5 \pm 4,0$ đến $61,2 \pm 9,7$ cá thể/ $/ \mathrm{m}^{2}$ (Hình $4 \mathrm{~b}$ ).

Trong khu vực nghiên cứu, nhóm các loài giáp xác nước ngọt và ấu trùng côn trùng thủy sinh có mật độ cá thể cao và chiếm ưu thế. Trong đó, loài tôm nước ngọt Macrobrachium sintangense thuộc lớp giáp xác phân bố ở tất cả các điểm thu mẫu qua tất cả các đợt khảo sát. Đây là loài chiếm ưu thế tại tất cả các điểm thu mẫu trong các đợt khảo sát mùa khô và chiếm ưu thế tại các điểm thu mẫu DK3, DK4 trong các đợt thu mẫu vào mùa mưa. Loài ấu trùng côn trùng bộ hai cánh Ablabesmyia sp. chỉ chiếm ưu thế tại điểm DK1 và DK2 trong các đợt khảo sát mùa mưa năm 2016 và năm 2017. 

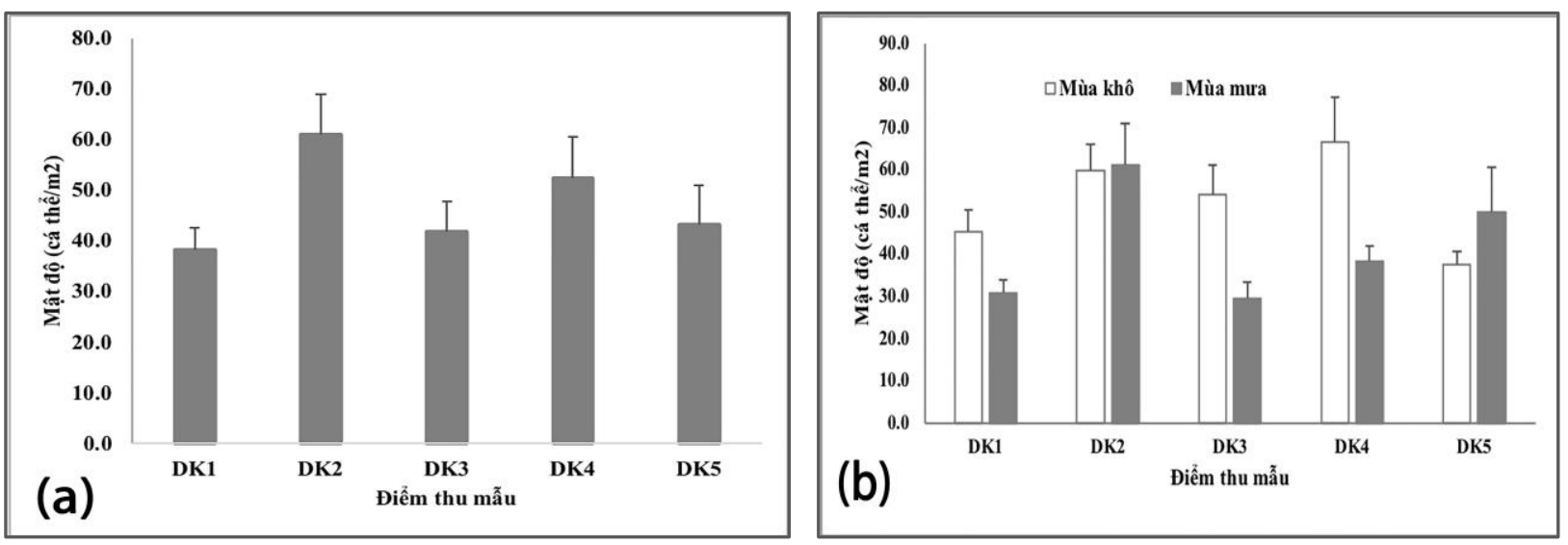

Hình 4. Mật độ cá thể động vật không xương sống cỡ lớn ven bờ tại các điềm thu mẫu

\subsection{Chi số đa dạng}

Chỉ số đa dạng Shannon-Weiner ( $\left.\mathrm{H}^{\prime}\right)$ trung bình tại các điểm thu mẫu dao động từ $0,4 \pm 0,3$ đến $0,9 \pm 0,5$. Trong đó, chỉ số đa dạng cao nhất tại điểm DK1 và thấp nhất tại điểm DK3 (Hình $5 a$ ).

Phân tích sự khác biệt về chỉ số đa dạng H’ của động vật không xương sống cỡ lớn ven bờ theo thời gian khảo sát và theo điểm thu mẫu bằng Two-way ANOVA cho thấy, chỉ số đa dạng không có sự khác biệt giữa các điểm thu mẫu ( $\mathrm{p}=0,060>0,05)$, nhưng có sự khác biệt giữa hai mùa khảo sát $(\mathrm{p}<0,05)$. Trong đó, chỉ số đa dạng trong đợt khảo sát mùa mưa trung bình dao động từ $0,7 \pm 0,2$ đến $1,1 \pm 0,3$ cao hơn so với đợt khảo sát mùa khô, trung bình dao động từ $0,1 \pm 0,1$ đến 0,7 $\pm 0,3$ (Hình 5b).
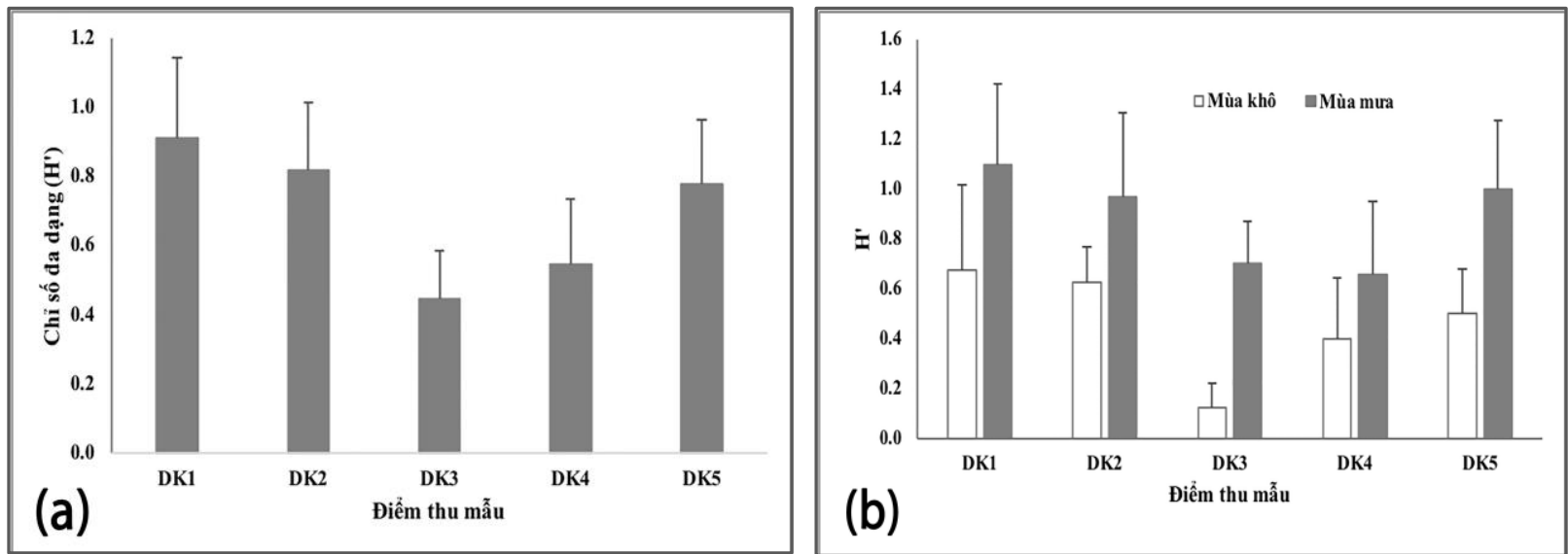

Hình 5. Chỉ số đa dạng H’ của động vật không xương sống cỡ lớn ven bờ tại các điểm thu mẫu

\section{Thảo luận}

Sự đa dạng của khu hệ động vật không xương sống cỡ lớn ven bờ phụ thuộc nhiều vào pH, nhiệt độ, sinh khối của sinh vật phù du, tảo bám đáy, đặc điểm môi trường nền đáy và độ che phủ của thực vật thuỷ sinh (Balcombe, Closs, \& Suter, 2007; MRC, 2010; Shibata et al., 2014). Trong đó, sự hiện diện của các loài thực vật thuỷ sinh ven bờ là môi trường sống của nhiều loài côn trùng thuỷ sinh và là yếu tố chủ yếu ảnh hưởng đến sự phân bố của các loài động vật không xương sống cỡ lớn ven bờ ở khu vực hồ (T. V. Le, Phan, Tran, \& Hoang, 2017). Ở khu vực hồ Đankia, khu vực xung quanh hồ là rừng thông và bãi cỏ trải rộng xuống đến mép hồ ở khu vực giữa hồ. Tại khu vực đập Đankia và cuối hồ có một số ít các loài thực vật thuỷ sinh phân bố và một số xác bã hữu cơ như cành cây, lá cây khô ở ven bờ hồ. Đây là môi trường thuận lợi cho các loài sống bơi lội tự 
do trong nước và nhóm các loài sống bò trườn trên các cá thể phân bố và phát triển như các loài côn trùng thuỷ sinh thuộc bộ hai cánh, bộ cánh nửa, bộ chuồn chuồn, nhóm các loài ốc nước ngọt và giáp xác (T. V. Le et al., 2017, 2018; Sychra, Adámek, \& Petřivalská, 2010). Trong đó các loài giáp xác nước ngọt có mật độ cao và chiếm ưu thế tại tất cả các điểm thu mẫu vào mùa khô. Vào mùa mưa là mùa sinh sản và phát triển của nhiều nhóm loài côn trùng, đặc biệt là nhóm các loài ấu trùng bộ hai cánh (T. V. Le et al., 2017). Chính vì vậy nhóm loài thuộc bộ hai cánh chiếm ưu thế tại một số điểm vào mùa mưa. Sự đa dạng về thành phần loài và mật độ phân bố cao của các loài động vật không xương sống cỡ lớn ven bờ cung cấp nguồn thức ăn giá trị cho các loài cá và chim di cư (Jolley, Albin, Kaemingk, \& Willis, 2013).

Khi môi trường sống càng đa dạng với nhiều kiểu sinh cảnh và chất nền khác nhau và độ che phủ thực vật thuỷ sinh càng cao thì số lượng loài của quần thể động vật không xương sống cỡ lớn ven bờ càng cao và ngược lại khi môi trường ít kiểu sinh cảnh và độ che phủ của thực vật thuỷ sinh thấp thì số lượng loài càng thấp (Brauns, Garcia, Walz, \& Pusch, 2007; Jolley et al., 2013). Do đó, số lượng loài động vật không xương sống cỡ lớn ven bờ ghi nhận được ở khu vực hồ là 23 loài thấp hơn so với nhiều vùng đất ngập nước khác có môi trường ven bờ với nhiều kiểu sinh cảnh và độ che phủ của thực vật thuỷ sinh cao như Khu bảo tồn Trà Sư, tỉnh An Giang (26 loài) (Phan et al., 2011), Khu bảo tồn đất ngập nước Láng Sen (43 loài) (T. V. Le et al., 2018), khu vực hồ xử lý nước thải Bình Hưng Hoà (26 loài) (T. V. Le et al., 2015).

Qua khảo sát cho thấy tại các điểm thu mẫu ở khu vực hồ không có nhiều khác biệt về môi trường nền đáy và sinh cảnh ven bờ, chính vì vậy mà số lượng loài, mật độ cá thể, chỉ số đa dạng sinh học không có sự khác biệt theo điểm thu mẫu ở khu vực hồ. Tuy nhiên, sự thay đổi mực nước ở các hồ chứa có ảnh hưởng và tác động mạnh đến mạng lưới thức ăn trong hồ và làm thay đổi cấu trúc quần xã động vật không xương sống cỡ lớn trong hồ (Furey, Nordin, \& Mazumder, 2006). Chính vì vậy, ở khu vực hồ có sự khác biệt rõ rệt về môi trường nền đáy ven bờ giữa hai mùa khảo sát, đặc biệt mùa khô, nền đáy ven bờ chỉ là bùn cát và rất ít các loài thực vật thuỷ sinh phân bố. Do đó số lượng loài và chỉ số đa dạng của động vật không xương sống cỡ lớn ven bờ ở khu vực hồ trong đợt khảo sát mùa khô thấp hơn so với mùa mưa.

\section{Kết luận}

Nghiên cứu khu hệ động vật không xương sống cỡ lớn ven bờ qua 5 năm khảo sát vào hai mùa trong năm ở khu vực hồ Đankia từ năm 2013 đến 2017 đã ghi nhận được 23 loài thuộc 15 họ, 9 bộ, 4 lớp, 3 ngành. Thành phần loài ở khu vực hồ đặc trưng bởi nhóm các loài phổ biến trong các thuỷ vực nước ngọt như ốc nước ngọt, giáp xác nước ngọt, ấu trùng côn trùng bộ hai cánh, bộ cánh nửa, bộ chuồn chuồn,... Trong đó, nhóm côn trùng bộ hai cánh có số loài cao nhất và nhóm tôm nước ngọt có mật độ cá thể cao nhất, ngược lại nhóm các loài giun ít tơ có số loài và mật độ cá thể thấp nhất.

Sự phân bố của khu hệ động vật không xương sống cỡ lớn ven bờ không có sự khác biệt về số lượng loài, mật độ cá thể, mức độ đa dạng giữa các điểm thu mẫu. Tuy nhiên có sự khác biệt về số loài và chỉ số đa dạng giữa hai mùa khảo sát. Trong đó, vào mùa mưa có số loài và chỉ số đa dạng của động vật không xương sống cỡ lớn ven bờ cao hơn mùa khô.

\section{Tài liệu tham khảo}

Balcombe, S. R., Closs, G. P., \& Suter, P. J. (2007). Density and distribution of epiphytic invertebrates on emergent macrophytes in a floodplain billabong. River Research and Applications, 23(8), 843-857. doi:10.1002/rra.1017 
Brauns, M., Garcia, X. F., Walz, N., \& Pusch, M. T. (2007). Effects of human shoreline development on littoral macroinvertebrates in lowland lakes. Journal of Applied Ecology, 44(6), 1138-1144. doi:10.1111/j.1365-2664.2007.01376.x

Dang, T. N., Thai, B. T., \& Pham, M. V. (1980). Định loại động vật không xưong sống miền Bắc Việt Nam [Identification of invertebrates in the North of Vietnam]. Hanoi, Vietnam: NXB Khoa học và Kỹ thuật.

Furey, P. C., Nordin, R. N., \& Mazumder, A. (2006). Littoral benthic macroinvertebrates under contrasting drawdown in a reservoir and a natural lake. Journal of the North American Benthological Society, 25(1), 19-31. doi:10.1899/0887-3593(2006)25[19:LBMUCD]2.0.CO;2

Jolley, J. C., Albin, E. S., Kaemingk, M. A., \& Willis, D. W. (2013). A survey of aquatic invertebrate communities in Nebraska sandhill lakes reveals potential alternative ecosystem states. Journal of Fish and Wildlife Management, 4(1), 151-162. doi:10.3996/082012-jfwm-072

Le, N. T. N., \& Phan, D. D. (2015). Đa dạng sinh học quần xã phù du ở hồ Đan Kia, huyện Lạc Dương, tỉnh Lâm Đồng [Biodiversity of plankton communities in Dan Kia lake, Lac Duong district, Lam Dong province]. Hội nghị Khoa học Toàn quốc về Sinh thái và Tài nguyên Sinh vật lần thút 6, 708-713. Retrieved March 10, 2019, from http://iebr.ac.vn/database/HNTQ6/708.pdf

Le, T. V., \& Do, L. T. B. (2015). Thành phần loài và một số chỉ số sinh học của động vật không xương sống cỡ lớn ven bờ ở sông Sài Gòn, đoạn chảy qua tỉnh Bình Dương [Species composition and some biological indicators of coastal large-sized invertebrates in Saigon River, stretching through Binh Duong province]. Hội Nghị Toàn Quốc về Sinh Thái và Tài Nguyên Sinh Vật lần thứ 6, 890-896. Retrieved March 20, 2019, from http://iebr.ac.vn/database/HNTQ6/890.pdf

Le, T. V., Phan, D. D., Tran, M. N. D., \& Hoang, H. D. (2017). Đa dạng thành phần loài côn trùng thuỷ sinh tại hồ xử lý nước thải Bình Hưng Hoà [Diversifying the composition of aquatic insects in Binh Hung Hoa wastewater treatment reservoir]. Tạp chí Phát triển Khoa học và Công nghẹ, 1(6), 117-126.

Le, T. V., Phan, D. D., Tran, M. N. D., Dang, S. V., Nguyen, T. V.z \& Luong, T. D. (2018). Thành phần loài và phân bố của động vật không xương sống cỡ lớn ven bờ ở Khu bảo tồn đất ngập nước Láng Sen [Species composition and distribution of coastal large-sized invertebrates in Lang Sen Wetland Reserve]. Tạp chí Khoa học và Công nghệ Việt Nam, 60(10), 18-22.

Le, T. V., Phan, D. D., Tran, T. V., \& Huynh, K. B. D. (2015). Dẫn liệu bước đầu về thành phần loài động vật không xương sống cỡ lớn ven bờ tại các hồ sinh học Bình Hưng Hoà, TP Hồ Chí Minh [Initial data on the composition of coastal large-sized invertebrates in the Binh Hung Hoa biological lakes, Ho Chi Minh City]. Hội Nghị Toàn Quốc về Sinh Thái và Tài Nguyên Sinh Vật lần thú 6, 897-902. Retrieved March 25, 2019, from http://iebr.ac.vn/database/HNTQ6/897.pdf

McCafferty, W. P. (1983). Aquatic entomology. The fishermen's and ecologists' illustrated guide to insects and their relatives. Boston, MA: Jones and Bartteth publishers.

Mekong River Commission. (2010). Biomonitoring methods for the lower Mekong basin. Vientiane, Laos PDR: Mekong River Commission.

Morse, J. C., Yang, L., \& Tian, L. (1994). Aquatic insects of the China useful for monitoring water quantily. Nanjing, China: Hobai University Press. 
Narumon, S., \& Boonsatien, B. (2006). Identification of freshwater invertebrates of the Mekong River and its tributaries. Vientiane, Laos PDR: Mekong River Commission.

Ngo, X. Q., Nguyen, V. S., Nguyen, D. T., Pham, V. L., \& Ngo, T. L. (2013). Biodiversity of littoral macroinvertebrates in the Mekong River. Tạp chi Khoa hoc - Đại hoc Su Pham TP. Hồ Chí Minh, 51, 16-28.

Nguyen, Q. X., Pinder, C., \& Tilling, S. (2001). Định loại các nhóm động vật không xương sống nuớc ngọt thwờng gặp ở Việt Nam [Groups classification of common freshwater invertebrates in Vietnam]. Hanoi, Vietnam: NXB Đại học Quốc gia Hà Nội.

Phan, D. D., Thai, T. N., Thai, T. T. M. T., Le, T. V., Huynh, Q. V. N., Le, N. T. N., \& Luu, H. T. P. (2011). Nghiên cứu đa dạng sinh học khu hệ thuỷ sinh vật và chất lượng môi trường nước ở Khu bảo vệ cảnh quan rừng tràm Trà Sư, tỉnh An Giang [Research on biodiversity of aquatic fauna and water environment's quality in Tra Su wetland protected area, An Giang province]. Hội Nghị Khoa Học Toàn Quốc về Sinh Thái và Tài Nguyên Sinh Vật lần thú 4, 542-549.

Rolf, A., \& Brandt, M. (1974). The non-marine aquatic Mollusca of Thailand. Frankfurt, Germany: Frankfurt am Main Senckenberg.

Shibata, J. Y., Karube, Z. I., Sakai, Y., Takeyama, T., Tayasu I., Yachi S., ...Okuda, N. (2014). Long-term and spatial variation in the diversity of littoral benthic macroinvertebrate fauna in Lake Biwa, Japan. In S. Nakano, T. Yahara, \& T. Nakashizuka (Eds.), Integrative observations and assessments (pp. 151-166). Tokyo, Japan: Springer.

Sychra, J., Adámek, Z., \& Petřivalská, K. (2010). Distribution and diversity of littoral macroinvertebrates within extensive reed beds of a lowland pond. Annales de LimnologieInternational Journal of Limnology, 46(4), 281-289. doi:10.1051/limn/2010026

Tran, T. T., Doan, H. N., Bui, H. N. L., \& Nguyen, T. T. T. (2015). Đánh giá mức độ ảnh hưởng của các nguồn nước chảy vào hồ Đan Kia và áp dụng mô hình Aquatox quản lý chất lượng nước hồ [Evaluating the impact of water sources flowing into Dan Kia reservoir and applying Aquatox model to manage lake water quality]. Tạ chí Sinh hoc, 38(1), 61-69. 